\title{
Fatores de Ajustamento para a Produção de Leite e Gordura na Raça Holandesa para Rebanhos do Estado de Minas Gerais
}

\author{
Marcus Cordeiro Durães ${ }^{1}$, Ary Ferreira de Freitas ${ }^{1}$, Nilson Milagres Teixeira ${ }^{1}$, José Valente ${ }^{1}$, \\ Mário Luiz Martinez ${ }^{1}$
}

\begin{abstract}
RESUMO - O objetivo deste trabalho foi calcular fatores de ajustamento para produção de leite e gordura, segundo a idade da vaca e a época de parto, para rebanhos da raça Holandesa do Estado de Minas Gerais. As análises estatísticas foram realizadas por intermédio da metodologia dos modelos mistos, usando-se máxima verossimilhança restrita em um modelo animal. Os efeitos fixos foram de rebanhoano, composição genética e classes de idade-época de parto e os efeitos aleatórios de animal (vaca, pai e mãe) e resíduo. Nesta análise foram usadas 49.666 lactações de 26.822 vacas, sendo 17.354 vacas puras por cruzamento (PC) e 9468 puras de origem (PO). Vinte e uma classes de idade foram formadas, sendo a menor constituída de vacas que pariram com menos de 24 meses e a maior, de vacas com mais de 99 meses de idade, por seis épocas de parto. Os fatores de ajustamento obtidos para produção de leite que foram superiores aos fatores de gordura, tenderam a ser menores para as vacas PO que os correspondentes aos valores estimados para as vacas PC. A média de produção de leite e gordura foi superior para as produções iniciadas na época correspondente no período de seca, principalmente para as vacas com mais de 30 meses de idade. As diferenças encontradas entre os fatores estimados para o período da seca em relação aos das águas foram mínimas, não ultrapassando 8\%. As produções de leite e gordura foram maiores para as vacas jovens.
\end{abstract}

Palavras-chave: época de parto, idade adulta, idade ao parto, vacas PC, vacas PO

\section{Adjustment Factors for Milk and Fat Yield in Holstein Breed Herds of Minas Gerais State}

ABSTRACT - The objective of this work was to calculate adjustment factors for milk and fat yield according to the cow age and calving season, for Holstein breeds herds from Minas Gerais State. The statistical analyses were made by means of mixed models, using Restricted Maximum Likelihood in an animal model. The fixed effects were herd-year, genetic composition and age classes-calving season, and as random effects of animal (cow, sire and dam) and error terms. Records used in the analysis were 49,666 lactations of 26,822 cows, being 17,354 from grades and 9,468 from purebred cows. Twenty-one age classes were made; with the small one constituted by cows that calving under 24 months and the large one by cow with more than 99 months of age, per six calving seasons. The adjustment factors attained for milk production, were which larger than for fat factors, tended to be smaller for purebred cows than the correspondent values estimated for grade cows. The average milk and fat production milk was higher for the productions beginning in the season corresponding to the dry season, mainly for cows with more than 30 months of age. The differences found among the estimated factors for the dry season in relation to the rainy season were minimal, not overpass $8 \%$. The milk and fat productions were higher for younger cows.

Key Words: season of calving, mature age, age of calving, purebred cows, grade cows

\section{Introdução}

Usualmente, os registros de produção são ajustados para os efeitos de idade e comparados dentro de subclasses rebanho-ano-estação, de tal maneira que os seus efeitos sejam removidos das lactações a serem avaliadas. Todavia, se os fatores não forem atualizados periodicamente, tornam-se inadequados para se obterem estimativas de produção de uma vaca à idade adulta.

Até a década de 70, nos Estados Unidos, os mesmos fatores multiplicativos eram usados para ambos os grupo de vacas não-registradas e registradas puro de origem (McDANIEL,1973). MILLER (1970) relatou os fatores de ajustamento que foram inicialmente utilizados nos rebanhos do Estado de Nova York, por volta de 1966, onde se detectou que as provas de touros eram severamente viesadas, quando todas as filhas de um touro pariam na mesma época do ano. Os fatores de ajustamento para época do parto e idade foram então calculados para reduzir os efeitos da flutuação sazonal nessas provas. KEOWN e EVERETT (1985) reestimaram os fatores de ajustamento para a produção de leite, gordura e proteína para a Região Leste dos Estados Unidos e observaram que os fatores para gordura foram maiores que os correspondentes para leite. Verificaram, também, 
que a interação dos efeitos da idade $\mathrm{x}$ mês de parto assume maior importância, quando a vaca se aproxima da idade adulta. POWELL e NORMAN (1986) concluíram que as vacas classificadas como "grades", equivalente no Brasil às vacas registradas como PC e com gerações controladas, produziram menos que as PO aos dois anos de idade; porém, notaram que esta diferença diminuiu ou desapareceu nas lactações subseqüentes, em razão de maior descarte das vacas classificadas como "grades". VanRADEN et al. (1995) relataram que os fatores de ajustamento para estação-idade ao parto diferem para vacas de mesma idade, com diferentes números de partos, bem como para diferentes épocas do ano. Segundo esses autores, os fatores para ajustamento de idade para vacas jovens são menores que os fatores anteriormente utilizados pelo USDA-DHIA e menos variáveis entre estações.

MARTINEZ et al. (1990) relataram os fatores de ajustamento de idade obtidos pelo método da Máxima Verossimilhança, que foram praticamente idênticos, quando o valor da repetibilidade utilizada variou de 0,2 a 0,8 . O estudo mostrou que este método é bastante eficiente quanto ao uso de diferentes valores para repetibilidade. MARTINEZ (1991), utilizando 60.257 lactações de 27.842 vacas da raça Holandesa, distribuídas em 549 rebanhos no Brasil, estimou fatores de ajustamento pelo método da Máxima Verossimilhança, considerando-se os efeitos simultâneos da idade e estação de parto sobre a produção de leite para três níveis de produção: baixo $(3660 \mathrm{~kg})$, médio $(4690 \mathrm{~kg})$ e alto $(5369 \mathrm{~kg})$. Independente do nível de produção, a idade de maior produção ocorreu entre sete e nove anos.

DUR ÃES e KEOWN (1991) estimaram os fatores de ajustamento para vacas Holandesas, registradas ou não, para leite, gordura e proteína, para os rebanhos americanos localizados em nove estados do meio-oeste, com o objetivo de atualizar os fatores de ajustamento utilizados na avaliação de touros.

O propósito do presente estudo foi estimar os fatores de ajustamento de idade-época de parto para a produção de leite e gordura dos rebanhos da raça Holandesa do Estado de Minas Gerais.

\section{Material e Métodos}

Foram utilizados dados coletados no período de 1988 a 1997 pelo serviço de controle leiteiro da Associação de Criadores de Gado Holandês de Minas Gerais (ACGHMG).

Foram eliminadas todas as lactações com dura- ção inferior a 240 dias, vacas com idade ao parto menor que 600 dias, lactações com encerramentos anormais e lactações em andamento. Dessa forma, foram excluídos 23,93\% do total dos dados (67.073 lactações). Também foram eliminadas as classes de rebanho-ano de parto com menos de cinco lactações, na tentativa de eliminar efeitos de controle leiteiro seletivo, o que resultou em redução adicional de 2,64\% dos dados. As lactações que tiveram controle leiteiro com base em três ordenhas foram ajustadas para duas.

Após a edição dos dados, utilizaram-se 49.666 lactações de 26.822 vacas mantidas em 380 rebanhos. As vacas foram agrupadas, segundo sua composição racial, em puras por cruzamento (PC) com gerações controladas e puras de origem (PO); cada grupo constituído, respectivamente, de 17.354 e 9468 vacas.

As estações da seca e das águas foram subdivididas em períodos de dois meses (outubro-novembro, dezembro-janeiro e fevereiro-março nas águas e abril-maio, junho-julho, agosto-setembro na seca). As idades ao parto foram distribuídas nas seguintes classes: menor que 24, subseqüientes de três em três meses até os 63 meses de idade e, daí em diante, de seis em seis meses até 99 meses, e o restante dos dados, em uma única classe, acima de 99 meses, perfazendo um total de 21 classes.

As análises estatísticas foram realizadas por intermédio da metodologia dos modelos mistos, usando máxima verossimilhança restrita (REML), adotando o seguinte modelo animal:

$$
\mathbf{Y}=\mathbf{H h}+\mathbf{Z a}+\mathbf{Z p}+\boldsymbol{\varepsilon}
$$

em que $\mathbf{Y}$ é o vetor das observações da produção de leite e de gordura, em até 305 dias; H, a matriz de incidência dos efeitos fixos, de rebanho-ano, composição genética (PC, PO) e classes de idade-época; $\mathbf{Z}$, a matriz de incidência dos efeitos aleatórios; $\boldsymbol{\varepsilon}$, o vetor de efeitos residuais; $\mathbf{h}$, o vetor dos efeitos fixos; a, o vetor de efeitos aleatórios de animal (vaca, pai e mãe); e p, o vetor dos efeitos permanentes aleatórios inerentes à repetição das observações de cada vaca.

Para obter os fatores, foi feita a suavização das constantes para cada idade-época, por intermédio do seguinte modelo: $\mathbf{c}=\mathbf{a}+\mathbf{b x}+\mathbf{b} \mathbf{x}^{2}+\mathbf{b x} \mathbf{x}^{3}$, em que $\mathbf{x}$ representa os efeitos linear, quadrático e cúbico do efeito da idade sobre as constantes e a e b são os parâmetros do polinômio. Os fatores multiplicativos de ajustamentos da produção de leite e gordura para idade-época foram obtidos das constantes estimadas para cada classe somadas à média geral $\mu$, para se obter média de produção para cada classe. O fator foi calculado pela seguinte fórmula: $\mathbf{f c}=(\mu+\mathbf{y a}) /(\mu+$ 
yc), em que $\mu$ representa a média geral; ya, a constante idade-época para as vacas que pariram na estação das águas (meses de fevereiro-março) e com idade entre 69 e 75 meses; e yc, a estimativa do efeito da idade-época para determinada classe de idade em cada uma das estações de parto.

\section{Resultados e Discussão}

As 21 classes de idade ao parto estão listadas na primeira coluna da esquerda de cada tabela, assim como as seis épocas do ano, correspondentes aos períodos das águas e da seca.

As médias de produção de leite e gordura para a mesma classe de idade foram maiores para as vacas PO. A amplitude de variação das médias de produção de leite foi menor no grupo PC $(4.539,5$ a $6299 \mathrm{~kg})$ em relação às $\mathrm{PO}(5.005,8$ e $7.110,8 \mathrm{~kg})$. O mesmo padrão para a produção de gordura foi observado para as vacas PC, cuja amplitude de variação foi de 155,0 a 209,2, enquanto para as vacas PO foi de 169,8 e $232,3 \mathrm{~kg}$ (Tabelas 1 e 2).

A média geral estimada foi de $5.865,54 \mathrm{~kg}$ de leite em 305 dias e duas ordenhas diárias e, para gordura, $196,85 \mathrm{~kg}$. A produção de leite analisada por MARTINEZ (1991), em rebanhos no Brasil, foi mais variável, levando-o a subdividir o conjunto de dados em três subconjuntos de acordo com a produção em baixa, média e alta. Para o subconjunto com produção mais alta, a média foi de $5369 \mathrm{~kg}$. A diferença na média de produção entre os valores observados por esse autor e os deste trabalho, possivelmente, ocorreu em virtude de os criadores do Estado de Minas Gerais manterem condições de manejo e alimentação mais uniformes e, também, por terem sido utilizadas apenas as lactações encerradas entre 1988 e 1997, enquanto o mencionado autor utilizou dados coletados entre 1975 e 1987, em diversos rebanhos de diferentes Estados do Brasil. Além disso, tem ocorrido melhoria genética nos rebanhos do Estado de Minas Gerais, como constatado por FREITAS et al. (1995). O ganho genético anual de 0,39\% para leite e 1,32\% para gordura, em relação à média, foi considerado razoável pelos autores. Além disso, FREITAS et al. (1998) estimaram o ganho para a produção de leite de $0,46 \pm 11$ $\mathrm{kg} / \mathrm{ano}$ para as vacas que pariram no período de 1987 a 1994, representando $0,01 \%$ da média do rebanho, e de $32,2 \pm 16 \mathrm{~kg} / \mathrm{ano}$ para as que pariram no período de 1990 a 1994, que, apesar de pequeno, representa acréscimo permanente na média, o que pode, de certa maneira, justificar a pequena diferença na produção de leite e gordura, entre os animais jovens e adultos.

As diferenças de produção de leite entre as vacas PC e PO para a mesma idade ao parto, possivelmente, podem ser explicadas pela melhor qualidade genética das vacas PO. Normalmente, o criador compra o sêmen de touros provados, reservando aqueles de touros considerados superiores para as melhores vacas. Além disso, pode ter ocorrido influência de manejo e alimentação, que pode ser difícil de se comprovar, quando se trata de dados já coletados. Observou-se ainda que a média de produção de leite foi superior para as vacas que pariram na seca, subclasse junho-julho (Tabela 1). Existe tendência das vacas que pariram no período de seca apresentarem produção mais elevada em relação ao período das águas. As vacas jovens parecem menos afetadas pelo estresse das altas temperaturas do verão que as vacas mais velhas. Esta mesma tendência foi notada por DURÃES e KEOWN (1991), que sugeriram maior concentração de partos para as vacas mais velhas na época mais propícia do ano, evitando-se os efeitos deletérios de temperaturas mais elevadas, enquanto as mais jovens poderiam parir em qualquer época do ano.

A média de produção de gordura foi maior no período da seca que nas águas, sendo maior para as vacas PO (Tabela 2). Atualmente, está havendo padronização do manejo na seca, com uso de silagem e feno, alimentando-se as vacas de acordo com a faixa de produção, independentemente do grau de sangue. Todavia, é ainda comum o criador reservar o sêmen de maior valor para as vacas mais valiosas, provocando com isto maior capacidade de produção para as vacas PO. Resultados similares foram encontrados por MILLER et al. (1970), KEOWN e EVERETT (1985) e DURÃES e KEOWN (1991), porém esses autores observaram que as vacas "grades", equivalentes ao grupo PC, tiveram produção de leite e gordura similar à das vacas $\mathrm{PO}$, com ligeira vantagem para as $\mathrm{PC}$.

As análises de regressão das constantes, para produção de leite sobre a idade, possibilitaram identificar efeitos lineares para os partos ocorridos em agosto-setembro, outubro-novembro e dezembrojaneiro e lineares e cúbicos para os partos ocorridos de fevereiro-março, abril-maio e junho-julho. Isto implica na necessidade de se fazer o ajustamento levando-se em conta fatores específicos para cada classe de idade-época de parto. Observaram-se também efeitos lineares para gordura, para os partos ocorridos entre dezembro-janeiro, fevereiro-março e outubro-novembro e efeito quadrático para os partos 
Tabela 1 - Média de produção de leite $(\mathrm{kg})$ para vacas da raça Holandesa em Minas Gerais Table 1 - Average milk yield in ( $\mathrm{kg})$ for Holstein cows in Minas Gerais State

\begin{tabular}{|c|c|c|c|c|c|c|}
\hline \multirow[t]{3}{*}{$\begin{array}{l}\text { Idade } \\
\text { Age }\end{array}$} & \multicolumn{6}{|c|}{ Época do parto } \\
\hline & \multicolumn{6}{|c|}{$\begin{array}{c}\text { Média de produção de leite para as vacas PC } \\
\text { Average milk yield for grade cows }\end{array}$} \\
\hline & $\begin{array}{l}\text { Out. - Nov. } \\
\text { Oct. }- \text { Nov. }\end{array}$ & $\begin{array}{l}\text { Dez. - Jan. } \\
\text { Dec. - Jan. }\end{array}$ & $\begin{array}{l}\text { Fev. - Mar. } \\
\text { Feb.-Mar. }\end{array}$ & $\begin{array}{l}\text { Abr. - Mai. } \\
\text { Apr.-May }\end{array}$ & $\begin{array}{l}\text { Jun. - Jul. } \\
\text { Jun. - Jul. }\end{array}$ & $\begin{array}{l}\text { Ago. - Set. } \\
\text { Aug. - Sep. }\end{array}$ \\
\hline$<24$ & (36) $5.173,1$ & (39) $5.727,8$ & (71) 5.435,9 & (78) 5.710,7 & (67) 5.542,9 & (71) $4.856,7$ \\
\hline $24-27$ & (227) 5.312,6 & (173) $5.471,7$ & (238) 5.576,3 & (363) 5.997,8 & (420) 5.637,1 & (369) 5.505,9 \\
\hline $27-30$ & (408) 5.154,7 & (380) 5.349,0 & (363) 5.448,0 & (440)5.663,5 & (506) 5.522,3 & $(520) 5.330,9$ \\
\hline $30-33$ & (350) 5.051,6 & (402) 5.087,8 & (419) 5.290,3 & (374) 5.225,0 & (353) 5.197,0 & (369) 5.050,9 \\
\hline $33-36$ & (191) 4.539,5 & (202) 4.737,4 & (265) 5.289,6 & (350) 5.466,4 & (311) 5.164,9 & (195) 5.015,3 \\
\hline $36-39$ & (171) $5.437,7$ & (169) 5.014,4 & (209) 5.297,5 & (339) 5.669,7 & (364) 5.802,3 & (320) $5.415,3$ \\
\hline $39-42$ & (274) 5.391,8 & (251) 5.494,6 & (257) 5.671,6 & (328) 5.882,4 & (349) 5.907,1 & (360) $5.715,7$ \\
\hline $42-45$ & (267) 5.596,5 & (295) 5.386,9 & (351)5.663,8 & (348) 5.782,0 & (346) 5.860,4 & (289) 5.623,7 \\
\hline $45-48$ & (209) 5.465,8 & (201)5.699,0 & (316) 5.740,8 & (368) 5.780,7 & (315) 5.779,3 & (224) 5.674,3 \\
\hline $48-51$ & (158) 5.470,0 & (134) $5.577,5$ & (226) 5.804,6 & (345) 5.856,4 & (311) 5.923,8 & (263) $5.834,4$ \\
\hline $51-54$ & (217) $5.612,1$ & (188) 5.646,8 & (219) 6.133,0 & (273) 6.047,6 & (236) 6.208,9 & (230) 6.165,1 \\
\hline $54-57$ & (186) 5.697,8 & (214) $5.751,3$ & (289) 5.835,8 & 6.035,8 & (196) 6.000,2 & (208) 5.907,9 \\
\hline $57-60$ & (128) 5.728,0 & (156) 5.545,6 & (257) $6.075,1$ & (330) 6.168,3 & (249) 5.974,2 & (178) 5.938,7 \\
\hline $60-63$ & (113) 5.795,1 & (124) 5.750,3 & (166) 6.078,0 & (279) 6.201,5 & (226) 5.983,6 & (211) 5.895,5 \\
\hline $63-69$ & (280) 5.783,3 & (263) 5.839,8 & (347) 5.966,8 & 6.290,3 & (344) 6.299,4 & (274) 6.099,4 \\
\hline $69-75$ & (161) 5.766,7 & (183) 5.699,0 & (290) 6.134,0 & (438) 6.203,6 & (357) 6.203,5 & (265) 5.924,3 \\
\hline $75-81$ & (213) 5.604,2 & (188) 5.732,0 & 6.090,8 & (246) $6.256,7$ & (218) $6.117,8$ & (218) $5.997,8$ \\
\hline $81-87$ & (106) 5.800,2 & (92) $6.077,2$ & (216) $6.151,3$ & (287) 5.938,7 & (247) 6.091,9 & (170) 6.083 .9 \\
\hline $87-93$ & (130) 5.678,0 & (141) 5.615,5 & (127) 5.535,3 & (162) 5.976,5 & (140) 6.286,6 & (122) $5.817,5$ \\
\hline $93-99$ & (71) $5.868,8$ & (76) $5.568,3$ & (122) 5.869,2 & (186) 6.191,5 & (164) 5.943,9 & (106) 5.770,9 \\
\hline$>99$ & (232) 5.471,9 & (267) 5.294,2 & (369) 5.443,0 & (431) 5.550,2 & (368) 5.800,3 & (295) 5.673,5 \\
\hline Idade & \multicolumn{6}{|c|}{ Época do parto } \\
\hline Age & \multicolumn{6}{|c|}{ Season of calving } \\
\hline \multicolumn{7}{|c|}{$\begin{array}{c}\text { Média de produção de leite para as vacas PO } \\
\text { Average milk yield for purebred cows }\end{array}$} \\
\hline & $\begin{array}{l}\text { Out. - Nov. } \\
\text { Oct. }- \text { Nov. }\end{array}$ & $\begin{array}{l}\text { Dez. - Jan. } \\
\text { Dec. -Jan. }\end{array}$ & $\begin{array}{l}\text { Fev. - Mar. } \\
\text { Feb.-Mar. }\end{array}$ & $\begin{array}{l}\text { Abr. - Mai. } \\
\text { Apr.-May }\end{array}$ & $\begin{array}{l}\text { Jun. - Jul. } \\
\text { Jun. - Jul. }\end{array}$ & $\begin{array}{l}\text { Ago. - Set. } \\
\text { Aug. -Sep. }\end{array}$ \\
\hline$<24$ & (45) $5.404,1$ & (41) 5.703,3 & (53) 5.824,2 & (52) 5.947,5 & (65) 5.794,7 & (44) 5.501,1 \\
\hline $24-27$ & (234) 5.847,7 & (172) 5.734,9 & (231)5.998,1 & (287) 6.164.6 & (378) 6.099,0 & (317) 5.955,2 \\
\hline $27-30$ & (281) 5.728,2 & (305) 5.750,9 & (285) 5.820,2 & (352) 6.088,1 & (360) 6.030,3 & (343) 5.831,2 \\
\hline $30-33$ & (171) 5.356,9 & (188) 5.464,2 & (261) 5.675,5 & (285) 5.767,8 & (218) 5.666,1 & (181) 5.610,0 \\
\hline $33-36$ & (84) $5.005,8$ & $(83) 5.701,6$ & (154) 5.588,2 & (179) $5.418,7$ & (142) $5.840,7$ & (116) 5566,1 \\
\hline $36-39$ & (103) 6.096,2 & (105) 6.029,7 & (108)5.856,9 & (200)5.986,5 & (213) $6.146,1$ & (182) 6.107,4 \\
\hline $39-42$ & (184) 6.040,5 & (148) 6.051,0 & (173) 6.148,8 & (206) 6.077,6 & (221) 6.435,7 & $6.379,5$ \\
\hline $42-45$ & (133) 6.010,2 & (147) 6.088,1 & 6.340,8 & (237) 6.169,1 & (172) 6.220,1 & (174) 6.429,0 \\
\hline $45-48$ & (97)5.898,5 & (88) 6.102,5 & (166) 6.547,5 & (184) 6.668,6 & 6.292,5 & (111) 6.155,1 \\
\hline $48-51$ & (81) 6.221,3 & (88) 5.938,7 & (110)6.282,2 & (163) 6.780,0 & (150) 6.413,0 & (125) $6.573,8$ \\
\hline $51-54$ & (99) $6.282,7$ & (106) $6.158,3$ & (114) 6.502,6 & (130) 6.432,5 & (135) 6.605,4 & (141) 6.632,6 \\
\hline $54-57$ & (97) 6.439,3 & (98) $6.246,3$ & (153) 6.282,4 & (185) 6.291,8 & (124) 6.231,2 & (119) $6.707,4$ \\
\hline $57-60$ & (68) 6.156,9 & (64) 6.362,4 & (120)6.792,4 & 6.395,8 & (142) 6.652,0 & (118) 6.704,7 \\
\hline $60-63$ & (67) 6.347,5 & (59) 6.386,2 & (95) 6.304,1 & (122) 6.490,2 & 7.110,8 & (99) 6.217,8 \\
\hline $63-69$ & (133) 6.210,1 & (128) 6.127,3 & (158) 6.433,4 & (213) 6.417,7 & 6.947,5 & (159) 6.604,9 \\
\hline $69-75$ & (109) 6.374,1 & (96) 5.932,8 & (137) 6.477,0 & (206) 6.796,7 & (179) 6.927,2 & (136) 6.758,5 \\
\hline $75-81$ & (106) 6.434,4 & (92) 6.112,0 & (121) $6.211,1$ & (140)6.684,8 & (121) $6.605,1$ & (107) 6.250,6 \\
\hline $81-87$ & (67) 6.239,4 & (64) 6.227,6 & (94) 6.371,6 & 6.819,3 (108) & (112) 6.746,2 & (75) $6.843,2$ \\
\hline $87-93$ & (53) 6.207,4 & (70) 5.994,0 & (71) 6.466,8 & (89) $6.479,0$ & (70) $6.225,7$ & (61) 6.246,9 \\
\hline $93-99$ & (48) 6.055,2 & (34) 5.574,9 & (58) 6.300,0 & (83) 6.286,0 & (72) $6.481,3$ & (44) $6.676,7$ \\
\hline$>99$ & (127) 5.644,3 & (136)5.930,6 & (170)6.145,6 & (188)5.990,4 & (194)5.972,8 & (172) 5.795,9 \\
\hline
\end{tabular}


Rev. bras. zootec.

Tabela 2 - Média de produção de gordura $(\mathrm{kg})$ para vacas da raça Holandesa em Minas Gerais Table 2 - Average fat yield in $(\mathrm{kg})$ for Holstein cows in Minas Gerais State

\begin{tabular}{ll}
\hline Idade & Época do parto \\
Age & Season of calving
\end{tabular}

Média de produção de gordura para as vacas PC

Average fat yield for grade cows

\begin{tabular}{|c|c|c|c|c|c|c|}
\hline & $\begin{array}{c}\text { Out. - Nov. } \\
\text { Oct. - Nov. }\end{array}$ & $\begin{array}{l}\text { Dez. - Jan. } \\
\text { Dec. -Jan. }\end{array}$ & $\begin{array}{c}\text { Fev. - Mar. } \\
\text { Feb.-Mar. }\end{array}$ & $\begin{array}{c}\text { Abr. - Mai. } \\
\text { Apr.-May }\end{array}$ & $\begin{array}{l}\text { Jun. - Jul. } \\
\text { Jun. - Jul. }\end{array}$ & $\begin{array}{l}\text { Ago. - Set. } \\
\text { Aug. - Sep. }\end{array}$ \\
\hline$<24$ & (35) 182,1 & (39) 191,1 & (71) 181,2 & (78) 192,7 & (67) 184,0 & (71) 166,3 \\
\hline $24-27$ & (227) 178,6 & (173) 181,6 & (237) 187,1 & (363) 195,8 & 187,7 & (369) 185,0 \\
\hline $27-30$ & (407) 173,6 & (380) 180,4 & (363) 182,5 & (440) 187,0 & (506) 185,1 & (520) 179,5 \\
\hline $30-33$ & (350) 170,3 & (401) 170,9 & (419) 177,4 & (374) 176,5 & (353) 174,0 & (369) 169,5) \\
\hline $33-36$ & (191) 155,0 & (202) 160,3 & (265) 177,0 & (350) 180,9 & (311) 173,5 & 170,5 (195) \\
\hline $36-39$ & (171) 182,6 & (169) 168,5 & (209) 178,5 & (339) 191,5 & (364) 190,6 & (320) 182,0 \\
\hline $39-42$ & (274) 180,3 & (250) 187,3 & (257) 191,1 & (328) 195,7 & (349) 197,7 & (360) 191,4 \\
\hline $42-45$ & (267) 187,0 & (295) 183,1 & (351) 190,7 & (348) 193,9 & (346) 196,8 & (289) 188,2 \\
\hline $45-48$ & 182,9 (209) & (201) 192,0 & (316) 193,1 & (368) 192,7 & (315) 195,0 & (224) 190,7 \\
\hline $48-51$ & (158) 182,4 & (134) 181,9 & (226) 193,2 & (345) 195,5 & (311) 197,0 & (263) 193,9 \\
\hline $51-54$ & (217) 187,8 & (188) 188,7 & (219) 203,3 & (273) 201,5 & (236 207,5 & (230) 205,1 \\
\hline $54-57$ & (186) 189,1 & (214) 191,5 & (289) 195,1 & (288) 201,7 & 197,8 & (208) 198,6 \\
\hline $57-60$ & (128) 192,3 & (156) 188,6 & (257) 204,2 & (330) 205,8 & (249) 200,6 & (178) 199,3 \\
\hline $60-63$ & (113) 195,2 & (124) 194,4 & (166) 202,6 & (279) 206,0 & (226) 200,2 & (211) 200,6 \\
\hline $63-69$ & (280) 192,1 & (263) 197,7 & (347) 200,4 & (392) 208,4 & (344) 209,2 & (273) 204,3 \\
\hline $69-75$ & (161) 192,7 & 191,0 & (290) 204,3 & (438) 207,6 & (357) 205,3 & (265) 199,5 \\
\hline $75-81$ & (213) 188,4 & (188) 194,5 & (229) 206,9 & (246) 209,2 & (218) 204,3 & (218) 200,3 \\
\hline $81-87$ & (106) 194,5 & (92) 204,0 & (216) 207,8 & (287) 200,2 & (247) 205,3 & (170) 205,4 \\
\hline $87-93$ & (130) 188,5 & (141) 185,2 & (127) 185,8 & (162) 200,3 & (140) 208,4 & (122) 194,2 \\
\hline $93-99$ & (71) 196,7 & (76) 189,8 & (122) 199,4 & (186) 204,2 & (164) 199,1 & (106) 193,2 \\
\hline$>99$ & (232) 186,0 & (267) 180,2 & (369) 181,1 & (431) 186,6 & (368 195,0 & (295) 191,3 \\
\hline
\end{tabular}

Idade Época do parto

Age

Season of calving

Média de produção de gordura para as vacas PO

Average fat yield for purebred cows

\begin{tabular}{lcccccc} 
& $\begin{array}{c}\text { Out. }- \text { Nov. } \\
\text { Oct. }- \text { Nov. }\end{array}$ & $\begin{array}{c}\text { Dez. }- \text { Jan. } \\
\text { Dec. }- \text { Jan. }\end{array}$ & $\begin{array}{c}\text { Fev. }- \text { Mar. } \\
\text { Feb. }- \text { Mar. }\end{array}$ & $\begin{array}{c}\text { Abr. - Mai. } \\
\text { Apr. }- \text { May }\end{array}$ & $\begin{array}{c}\text { Jun. - Jul. } \\
\text { Jun. }- \text { Jul. }\end{array}$ & $\begin{array}{c}\text { Ago. - Set. } \\
\text { Aug. }- \text { Sep. }\end{array}$ \\
\hline$<24$ & $(45) 189,5$ & $(41) 195,2$ & $(53) 197,1$ & $(52) 194,4$ & $(65) 198,0$ & $(44) 190,5$ \\
$24-27$ & $(234) 198,9$ & $(172) 195,5$ & $(231) 201,2$ & $(287) 203,6$ & $(378) 202,4$ & $(314) 199,8$ \\
$27-30$ & $(281) 196,2$ & $(305) 193,2$ & $(285) 195,8$ & $(352) 205,7$ & $(360) 203,7$ & $(340) 197,5$ \\
$30-33$ & $(170) 183,8$ & $(188) 186,5$ & $(261) 193,6$ & $(285) 195,2$ & $(218) 192,5$ & $(181) 190,8$ \\
$33-36$ & $(84) 169,8$ & $(83) 194,9$ & $(154) 190,7$ & $(179) 181,2$ & $(142) 196,3$ & $(116) 189,8$ \\
$36-39$ & $(103) 2085$ & $(105) 200,5$ & $(108) 197,6$ & $(200) 201,5$ & $(213) 205,5$ & $(182) 202,5$ \\
$39-42$ & $(184) 201,1$ & $(148) 206,4$ & $(173) 209,5$ & $(206) 206,2$ & $(221) 214,5$ & $(208) 211,6$ \\
$42-45$ & $(132) 202,2$ & $(147) 204,4$ & $(219) 214,8$ & $(237) 208,4$ & $(172) 208,0$ & $(174) 214,4$ \\
$45-48$ & $(97) 195,5$ & $(88) 209,5$ & $(166) 221,8$ & $(184) 227,0$ & $(153) 211,0$ & $(111) 207,9$ \\
$48-51$ & $(81) 201,5$ & $(88) 200,6$ & $(110) 213,9$ & $(163) 227,1$ & $(150) 213,6$ & $(125) 219,7$ \\
$51-54$ & $(99) 213,2$ & $(106) 205,2$ & $(114) 219,2$ & $(130) 213,2$ & $(135) 221,8$ & $(141) 220,3$ \\
$54-57$ & $(97) 215,2$ & $(98) 211,5$ & $(153) 211,9$ & $(185) 213,6$ & $(124) 208,3$ & $(119) 221,0$ \\
$57-60$ & $(68) 210,5$ & $(64) 214,5$ & $(120) 224,9$ & $(171) 213,2$ & $(142) 221,7$ & $(117) 222,7$ \\
$60-63$ & $(67) 207,9$ & $(59) 217,4$ & $(95) 213,7$ & $(122) 218,2$ & $(100) 232,3$ & $(99) 207,1$ \\
$63-69$ & $(132) 212,4$ & $(128) 208,3$ & $(158) 215,8$ & $(213) 218,4$ & $(178) 228,2$ & $(159) 219,1$ \\
$69-75$ & $(109) 218,7$ & $(96) 202,0$ & $(137) 216,2$ & $(206) 2305$ & $(178) 230,9$ & $(136) 225,7$ \\
$75-81$ & $(106) 215,9$ & $(92) 205,9$ & $(121) 207,6$ & $(140) 223,4$ & $(121) 218,6$ & $(106) 211,4$ \\
$81-87$ & $(67) 210,1$ & $(64) 210,1$ & $(94) 215,2$ & $(108) 229,5$ & $(112) 222,9$ & $(74) 232,2$ \\
$87-93$ & $(53) 208,7$ & $(69) 203,4$ & $(71) 216,7$ & $(89) 218,8$ & $(70) 208,9$ & $(61) 210,6$ \\
$93-99$ & $(47) 203,7$ & $(34) 195,3$ & $(58) 209,0$ & $(83) 215,8$ & $(72) 219,4$ & $(44) 220,4$ \\
$>99$ & $(127) 193,1$ & $(136) 203,7$ & $(170) 209,0$ & $(188) 203,4$ & $(194) 201,6$ & $(172) 195,6$ \\
\hline
\end{tabular}


ocorridos entre agosto-setembro e linear e cúbico para os partos de abril-maio e junho-julho. O coeficiente de determinação, $\mathrm{R}^{2}$ ajustado, variou de 0,85 a 0,94, sendo similar ao relatado por MARTINEZ (1991).

Para as vacas mais novas e mesma idade, os fatores tenderam a ser mais baixos entre abril e julho e mais elevados nas outras épocas do ano. De maneira geral, os fatores calculados foram menores para os partos ocorridos no período da seca, praticamente para todas as classes de idade. Apesar de a diferença ser mínima, cerca de $2 \%$, os fatores para as vacas PO foram menores que os das vacas PC.

Os fatores descritos na Tabela 3 foram menores que os descritos por MARTINEZ (1991) para a raça
Holandesa no Brasil. Todavia, os fatores de ajustamento calculados neste trabalho foram similares aos relatados por DURÃES e KEOWN (1991), que utilizaram 419.860 lactações coletadas em nove Estados do meio-Oeste dos Estados Unidos.

Os fatores de ajustamento para as vacas mais jovens foram similares aos descritos por COOPER e HARGROVE (1982), porém inferiores aos descritos por DURÃES e KEOWN (1991) e MARTINEZ (1991). Este autor salientou que as vacas mais jovens deveriam ter acréscimo de até $41 \%$ para produção de leite como ajustamento para a idade adulta. Estes fatores superaram, aproximadamente, $10 \%$ os fatores descritos na Tabela 3; seu uso contínuo poderia causar

Tabela 3 - Fatores de ajustamento para a produção de leite de acordo com a classe de idade e época do parto para vacas puras de origem (PO) e puras por cruzamento (PC) da raça Holandesa em Minas Gerais

Table 3 - Adjustment factors for milk yield according with age classes and calving season for purebred registered (PO) and grade (PC) of the Holstein breed cows in Minas Gerais State

\begin{tabular}{|c|c|c|c|c|c|c|c|c|c|c|c|c|}
\hline \multirow[t]{4}{*}{$\begin{array}{l}\text { Idade } \\
\text { Age }\end{array}$} & \multicolumn{12}{|c|}{$\begin{array}{l}\text { Estação do ano } \\
\text { Season of the year }\end{array}$} \\
\hline & \multicolumn{6}{|c|}{$\begin{array}{c}\text { Água } \\
\text { Rainny season }\end{array}$} & \multicolumn{4}{|c|}{$\begin{array}{c}\text { Seca } \\
\text { Dry season }\end{array}$} & & \\
\hline & \multicolumn{2}{|c|}{$\begin{array}{l}\text { Oct.- Nov. } \\
\text { Oct.- Nov. }\end{array}$} & \multicolumn{2}{|c|}{$\begin{array}{l}\text { Dez.- Jan. } \\
\text { Dec. - Jan. }\end{array}$} & \multicolumn{2}{|c|}{$\begin{array}{c}\text { Fev. - Mar. } \\
\text { Feb.-Mar. }\end{array}$} & \multicolumn{2}{|c|}{$\begin{array}{l}\text { Abr.-Mai. } \\
\text { Apr. - May }\end{array}$} & \multicolumn{2}{|c|}{$\begin{array}{c}\text { Jun. - Jul. } \\
\text { Jun. - Jul. }\end{array}$} & \multicolumn{2}{|c|}{$\begin{array}{l}\text { Ago. - Set. } \\
\text { Aug. - Sep. }\end{array}$} \\
\hline & $\mathrm{PO}$ & $\mathrm{PC}$ & $\mathrm{PO}$ & $\mathrm{PC}$ & $\mathrm{PO}$ & $\mathrm{PC}$ & $\mathrm{PO}$ & $\mathrm{PC}$ & $\mathrm{PO}$ & $\mathrm{PC}$ & $\mathrm{PO}$ & $\mathrm{PC}$ \\
\hline$<24$ & 1,30 & 1,30 & 1,26 & 1,27 & 1,26 & 1,26 & 1,22 & 1,23 & 1,24 & 1,24 & 1,29 & 1,28 \\
\hline $24-27$ & 1,25 & 1,26 & 1,24 & 1,24 & 1,23 & 1,23 & 1,19 & 1,21 & 1,20 & 1,22 & 1,25 & 1,24 \\
\hline $27-30$ & 1,21 & 1,22 & 1,22 & 1,21 & 1,20 & 1,20 & 1,16 & 1,19 & 1,17 & 1,19 & 1,21 & 1,21 \\
\hline $30-33$ & 1,17 & 1,19 & 1,19 & 1,18 & 1,17 & 1,18 & 1,14 & 1,17 & 1,14 & 1,16 & 1,17 & 1,17 \\
\hline $33-36$ & 1,14 & 1,16 & 1,17 & 1,16 & 1,15 & 1,15 & 1,11 & 1,14 & 1,11 & 1,14 & 1,14 & 1,14 \\
\hline $36-39$ & 1,12 & 1,13 & 1,15 & 1,13 & 1,12 & 1,13 & 1,09 & 1,12 & 1,09 & 1,11 & 1,11 & 1,11 \\
\hline $39-42$ & 1,10 & 1,10 & 1,13 & 1,11 & 1,10 & 1,10 & 1,05 & 1,10 & 1,07 & 1,08 & 1,09 & 1,09 \\
\hline $42-45$ & 1,08 & 1,08 & 1,11 & 1,09 & 1,08 & 1,08 & 1,04 & 1,08 & 1,05 & 1,06 & 1,07 & 1,07 \\
\hline $45-48$ & 1,06 & 1,06 & 1,09 & 1,07 & 1,06 & 1,06 & 1,02 & 1,06 & 1,03 & 1,04 & 1,05 & 1,05 \\
\hline $48-51$ & 1,05 & 1,05 & 1,08 & 1,06 & 1,05 & 1,05 & 1,01 & 1,04 & 1,02 & 1,02 & 1,03 & 1,03 \\
\hline $51-54$ & 1,04 & 1,03 & 1,06 & 1,04 & 1,03 & 1,03 & 1,00 & 1,02 & 1,01 & 1,00 & 1,02 & 1,02 \\
\hline $54-57$ & 1,03 & 1,02 & 1,05 & 1,03 & 1,02 & 1,02 & 0,99 & 1,01 & 1,00 & 0,99 & 1,01 & 1,01 \\
\hline $57-60$ & 1,03 & 1,01 & 1,04 & 1,02 & 1,01 & 1,01 & 0,98 & 1,00 & 0,99 & 0,98 & 1,00 & 1,00 \\
\hline $60-63$ & 1,02 & 1,01 & 1,03 & 1,02 & 1,01 & 1,00 & 0,98 & 0,99 & 0,98 & 0,97 & 1,00 & 0,99 \\
\hline Idade & & & & & & Est & do a & & & & & \\
\hline Age & & & & & & Seaso & the ye & & & & & \\
\hline
\end{tabular}

\begin{tabular}{|c|c|c|c|c|c|c|c|c|c|c|c|c|}
\hline & \multicolumn{6}{|c|}{$\begin{array}{c}\text { Água } \\
\text { Rainny season }\end{array}$} & \multicolumn{5}{|c|}{$\begin{array}{c}\text { Seca } \\
\text { Dry season }\end{array}$} & \\
\hline & \multicolumn{2}{|c|}{$\begin{array}{l}\text { Oct.- Nov. } \\
\text { Oct.- Nov. }\end{array}$} & \multicolumn{2}{|c|}{$\begin{array}{l}\text { Dez.- Jan. } \\
\text { Dec. - Jan. }\end{array}$} & \multicolumn{2}{|c|}{$\begin{array}{c}\text { Fev. - Mar. } \\
\text { Feb.-Mar. }\end{array}$} & \multicolumn{2}{|c|}{$\begin{array}{l}\text { Abr.-Mai. } \\
\text { Apr. - May }\end{array}$} & \multicolumn{2}{|c|}{$\begin{array}{c}\text { Jun. - Jul. } \\
\text { Jun. - Jul. }\end{array}$} & \multicolumn{2}{|c|}{$\begin{array}{l}\text { Ago. - Set. } \\
\text { Aug. - Sep. }\end{array}$} \\
\hline & $\mathrm{PO}$ & $\mathrm{PC}$ & $\mathrm{PO}$ & $\mathrm{PC}$ & $\mathrm{PO}$ & $\mathrm{PC}$ & $\mathrm{PO}$ & $\mathrm{PC}$ & $\mathrm{PO}$ & $\mathrm{PC}$ & $\mathrm{PO}$ & $\mathrm{PC}$ \\
\hline $63-69$ & 1,02 & 1,00 & 1,03 & 1,02 & 1,00 & 1,00 & 0,97 & 0,98 & 0,98 & 0,96 & 0,99 & 0,99 \\
\hline $69-75$ & 1,01 & 1,00 & 1,02 & 1,02 & 1,00 & 1,00 & 0,97 & 0,97 & 0,97 & 0,96 & 0,99 & 0,99 \\
\hline $75-81$ & 1,01 & 1,00 & 1,02 & 1,02 & 1,00 & 1,00 & 0,97 & 0,97 & 0,97 & 0,96 & 0,99 & 0,99 \\
\hline $81-87$ & 1,01 & 1,00 & 1,02 & 1,03 & 1,00 & 1,01 & 0,98 & 0,98 & 0,97 & 0,97 & 0,99 & 1,00 \\
\hline $87-93$ & 1,01 & 1,01 & 1,03 & 1,04 & 1,01 & 1,02 & 0,99 & 0,99 & 0,97 & 0,98 & 0,99 & 1,00 \\
\hline $93-99$ & 1,00 & 1,02 & 1,04 & 1,06 & 1,02 & 1,03 & 1,00 & 1,00 & 0,98 & 0,99 & 1,00 & 1,01 \\
\hline$>99$ & 1,00 & 1,03 & 1,05 & 1,08 & 1,03 & 1,05 & 1,00 & 1,02 & 0,99 & 1,01 & 1,01 & 1,03 \\
\hline
\end{tabular}


Rev. bras. zootec.

superestimação na produção de leite à idade adulta.

A produção máxima, usualmente, é alcançada quando os animais atingem a idade adulta. MARTINEZ (1991) descreveu esta idade para as vacas que pariram no período das águas com 85 a 96 meses. No presente trabalho, observou-se que, à medida que os animais cresciam, a idade a produção também aumentava, até as vacas alcançarem a produção máxima, que ocorreu em torno de 69-75 meses. A diferença entre os fatores estimados para os períodos da seca e das águas foi reduzida gradativamente.
Os fatores de ajustamento para gordura apresentados na Tabela 4 são inferiores em até $8 \%$ aos valores descritos por DURÃES e KEOWN (1991), para os animais com menos de 36 meses de idade. A partir desta idade, a diferença é mínima ou inexistente.

Os fatores apresentados para leite e gordura diferem entre si, sugerindo o uso de fatores específicos para cada característica. Mudanças no manejo sugerem o uso de modelos para a avaliação genética que considerem, simultaneamente, os efeitos da idade e época de parto.

Tabela 4 - Fatores de ajustamento para a produção de gordura de acordo com a classe de idade e época do parto para vacas puras de origem (PO) e puras por cruzamento (PC) da raça Holandesa em Minas Gerais

Table 4 - Mature equivalent factors for fat yield by age and month of freshing for purebred registered (PO) and grade registered (PC) Holstein cows in Minas Gerais State

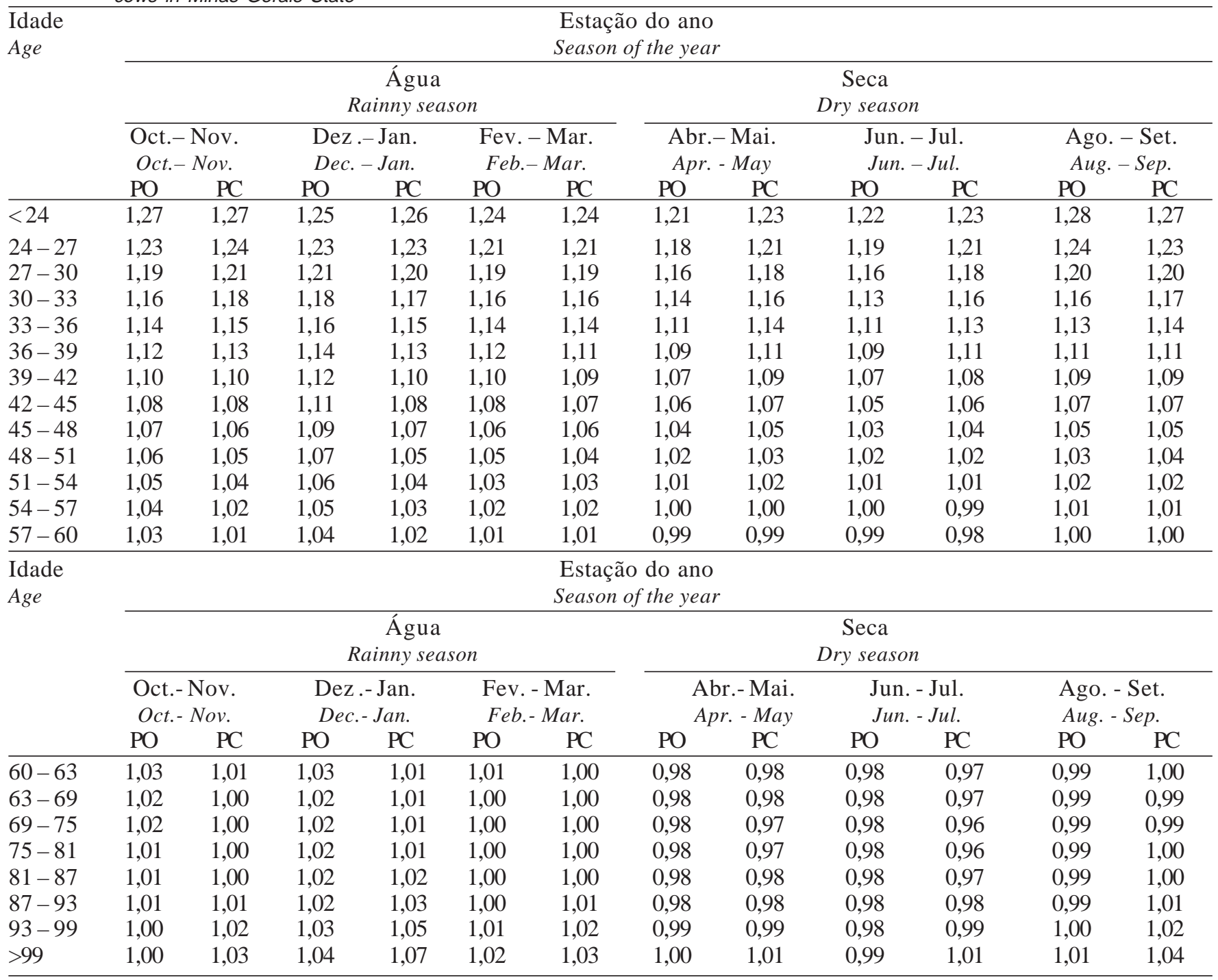




\section{Conclusões}

Existem diferenças mínimas entre os fatores de ajustamentos calculados para as épocas dos partos. A média de produção dos diferentes partos ocorridos na época seca foi ligeiramente superior à ocorrida na época das águas. Os produtores de leite parecem estar padronizando o nível de nutrição e manejo do rebanho, fazendo com que a produção de leite e gordura fosse semelhante em ambas estações. Como esperado, os fatores de ajustamento foram maiores para vacas jovens, decrescendo à medida que as vacas envelhecem. Existe forte tendência das vacas $\mathrm{PO}$ produzirem mais leite e gordura que as PC.

\section{Referências Bibliográficas}

COOPER, J.B, HARGROVE, G.L. 1982. Age and month of calving adjustment of Holstein protein, milk, and fat lactation yields. J. Dairy Sci., 65(8):1673-1678.

DURÃES, M. C., KEOWN, J. F. 1991. Age-month factors. Mature equivalent factors for three yield traits for non-registered and registered cattle. Rev. Bras. Genet., 14(3):713-728.

FREITAS, A.F., VERNEQUE, R.S., TEIXEIRA, N.M., et al. Estimativas de tendências genéticas em gado Holandês do Estado de Minas Gerais. REUNIÃO ANUAL DA SOCIEDADE BRASILEIRA DE ZOOTECNIA, 32, 1995, Brasília. Anais...Brasília: SBZ, 1995, p.660-661.

FREITAS, A.F., DURÃES, M.C., TEIXEIRA, N.M. Parâmetros genéticos da produção de leite de animais da raça Holandesa mantidos em sistema intensivo do tipo "Free Stall". In: REUNIÃO ANUAL DA SOCIEDADE BRASILEIRA DE ZOOTECNIA, 34, 1998, Botucatu. Anais... Botucatu: SBZ, 1998 , p.470-472.
KEOWN, J.F., EVERETT, R.W. 1985. Age-month adjustment factors for milk, fat, and protein yields in Holstein cattle. $J$. Dairy Sci., 68(10):2664-2669.

MARTINEZ, M.L., LEE, A.J., LIN, C.Y. 1990. Multiplicative age-season adjustment factors by maximum likelihood, gross and paired comparison procedures. J. Dairy Sci., 73(3):819825.

MARTINEZ, M.L. 1991. Fatores multiplicativos de ajuste da produção de leite na raça Holandesa, para os efeitos simultâneos da idade ao parto e estação de parição. Pesq. Agropec. Bras., 26(10):1761-1770.

McDANIEL, B.T. 1973. Merits and problems of ajusting to other than mature age. J. Dairy Sci., 56(7):959-967.

MILLER, P.D., LENTZ, W.E., HENDERSON, C.R. 1970. Join influence of month and age of calving on milk of Holstein cows in the Northeastern United States. J. Dairy Sci., 53(3):351-357.

POWELL, R.L., NORMAN, H.D. 1986. Genetic and environment differences between registered and grade Holstein cows. $J$. Dairy Sci., 69(11):2897-2907.

VANRADEN, P.M., WIGGANS, G.R., POWELL, R. L. et al. 1995. Changes in USDA-DHIA genetic evaluations. Beltsville, MD. 3p.

Recebido em: 29/12/98

Aceito em: 22/03/99 